\title{
Patient-centred care: confessions of a pragmatist
}

\section{Kenneth EF Sands}

\section{Correspondence to}

Dr Kenneth EF Sands, Beth Israel Deaconess Medical Center, 330

Brookline Ave, Boston MA 02215, USA; ksands@bidmc. harvard.edu

Accepted 11 January 2016 Published Online First 28 January 2016

\section{CLlinked}

- http://dx.doi.org/10.1136/ bmjqs-2015-004561

\section{CrossMark}

To cite: Sands KEF. BMJ Qual Saf 2016;25:909-910.
The essential importance of patientcentredness is no longer in dispute. More than 15 years ago, the Institute of Medicine incorporated patient-centred care as elemental to the definition of quality care. ${ }^{1}$ In his 2009 'Confessions of an Extremist' essay, Sir Donald Berwick goes further, arguing that patientcentredness is 'not a route to the point; it is the point'. ${ }^{2}$ At the same time, we all recognise that our current systems do not optimise patient centredness. At our institution, we have begun tracking episodes of 'disrespect' with the same systems we use to track patient safety events, and are learning that these emotional harms are more common than the physical harms we have tracked so rigorously for many years. ${ }^{3}$ The case has been made and the challenge accepted: we need to reconfigure care delivery to be more patient-centred.

The challenge now is how best to achieve that reconfiguration, using evidence-based interventions. Yes, there is a solid literature that demonstrates patient-centred care interventions improve clinical outcomes, ${ }^{4}$ but there remains a yawning knowledge gap regarding what works to improve patient centredness within the staggering complexity of everyday clinical operations. In the current environment, where all resources are stretched and all healthcare workers are overextended, we need to know which care delivery innovations offer the most promise.

Thus, we owe our thanks to O'Leary and colleagues for pursuing formal analysis of their trial of Patient-Centered Bedside Rounds (PCBR) at Northwestern Memorial Hospital in Chicago. ${ }^{5}$ PCBR have been described previously, and are especially popular in paediatric hospitals. But data on their impact on patient activation and patient satisfaction, especially in the adult setting, remain scant. O'Leary et al pursued a well-planned intervention on two non-teaching inpatient units, which previously operated under a model of structured interdisciplinary rounds (the implementation of which has been the subject of previous publications by the author). ${ }^{6}$ PCBR were designed with input from the hospital Patient and Family Advisory Council, and was initiated after 6 weeks of planning by an interdisciplinary team. The evaluation compared PCBR with care in control units using three different instruments, designed to capture both patient activation and patient satisfaction; healthcare worker perceptions were formally assessed as well. Hundreds of patients were enrolled, and the study was reasonably powered. Results in the end showed no significant difference in patient activation or satisfaction, and a perception among clinicians that while communication may have improved, the impact on workflow efficiency was not favourable.

Why the surprising lack of measurable impact? Should not one assume that PCBR would be perceived by patients as a better experience? The authors point out that several issues may have prevented the detection of favourable impact of PCBR. First, exposure to PCBR on the intervention units was only $54 \%$, substantially less than the stated goal of $75 \%$ and thus diluting the opportunity to measure a difference relating to the intervention. Second, comparison was being made to inpatient units that had previously implemented an advanced model of interdisciplinary rounds, and the incremental benefit to PCBR may have been less than what would have been seen in comparison with a more traditional inpatient rounding model. Third, the authors note that the selected format of PCBR and/or its execution (which was not assessed) may have been inadequate to create an effect. One additional possibility is that the implementation of PCBR disrupted workflow in some unfavourable 
way that was perceptible to patients, and counterbalanced any positive effect. While not quantified, the authors report that comments from healthcare workers suggest a perception that workflow was negatively impacted, and rounds were less efficient.

In fact, this is perhaps the most significant contribution of this publication: the authors recognised the potential for real tradeoffs in efficiency as part of PCBR implementation, and formally evaluated the workflow impact of their intervention. This is an essential observation for all of us working to achieve patient-centredness, or in fact any significant change effort in the dynamic clinical environment: while trying to optimise one process, we must monitor the impacts on other processes.

Of course, one can only know if we are making things better or worse if we formally study the interventions, and this needs to happen much more frequently. Right now, there are likely many hospitals experimenting with PCBR, but it is unlikely that they are approaching the implementation with the same level of rigour and assessment strategy that was pursued by O'Leary et al. So these tests of change we will bring us no closer to truly understanding, in any formal way, the pathway to patient centredness. We need to advance and expand the concept of healthcare delivery science, bringing rigorous evaluation to service delivery. In the mean time, we remain largely in an evidence-free zone regarding the optimal way to make our clinical processes more patient-centred.

We should aspire to reach the extremist vision of Sir Berwick, but getting there will require pragmatism.
We need to learn to get better at monitoring patientcentredness, distinct from patient satisfaction. We need to measure adverse outcomes with the same rigour that we bring to patient safety events, using root cause analysis to drive corrective action. We need to formally evaluate interventions, and share important learnings, even when some of the findings are inconclusive. The learning will be incremental, but the opportunity to improve our operations on behalf of our patients is substantial.

Competing interests None declared.

Provenance and peer review Commissioned; internally peer reviewed.

\section{REFERENCES}

1 Institute of Medicine. Crossing the quality chasm: a new health system for the 21st century. Washington DC: National Academy Press, 2001.

2 Berwick DC. What 'patient-centered' should mean: confessions of an extremist. Health Aff 2009;28:w555-65.

3 Sokol-Hessner L, Folcarelli PH, Sands KEF. Emotional harm from disrespect: the neglected preventable harm. BMJ Qual Saf 2015;24:550-3.

4 Coulter A, Ellins J. Effectiveness of strategies for informing, educating, and involving patients. BMJ 2007;335:24-7.

5 O'Leary KJ, Killarney A, Hansen LO, et al. Effect of patient-centred bedside rounds on hospitalised patients' decision control, activation and satisfaction with care. BMJ Qual Saf 2016;25:921-8.

6 O'Leary KJ, Creeden AJ, Slade ME, et al. Implementation of unit-based interventions to improve teamwork and patient safety on a medical service. Am J Med Qual 2015;30:409-16. 